\title{
TRIM28 Regulates Dlk1 Expression in Adipogenesis
}

\author{
Hsin-Pin Lu ${ }^{1}{ }^{\oplus}$, Chieh-Ju Lin ${ }^{1}$, Wen-Ching Chen $\left.{ }^{1}{ }^{(}\right)$, Yao-Jen Chang ${ }^{2}{ }^{(}$, Sheng-Wei Lin ${ }^{2}{ }^{(}$, \\ Hsin-Hui Wang ${ }^{3,4,5}$ and Ching-Jin Chang 1,2,* \\ 1 Graduate Institute of Biochemical Sciences, College of Life Science, National Taiwan University, \\ Taipei 10617, Taiwan; phoebe1620@gmail.com (H.-P.L.); ma8374@hotmail.com (C.-J.L.); \\ a0972718683@gmail.com (W.-C.C.) \\ 2 Institute of Biological Chemistry, Academia Sinica, Taipei 11529, Taiwan; ntugeorge@gmail.com (Y.-J.C.); \\ sanway@gate.sinica.edu.tw (S.-W.L.) \\ 3 Department of Pediatrics, Division of Pediatric Immunology and Nephrology, Taipei Veterans General \\ Hospital, Taipei 11217, Taiwan; hhwang@vghtpe.gov.tw \\ 4 Department of Pediatrics, Faculty of Medicine, School of Medicine, National Yang-Ming University, \\ Taipei 11217, Taiwan \\ 5 Institute of Emergency and Critical Care Medicine, School of Medicine, National Yang-Ming University, \\ Taipei 11217, Taiwan \\ * Correspondence: chingjin@gate.sinica.edu.tw
}

Received: 26 August 2020; Accepted: 27 September 2020; Published: 30 September 2020

\begin{abstract}
The tripartite motif-containing protein 28 (TRIM28) is a transcription corepressor, interacting with histone deacetylase and methyltransferase complexes. TRIM28 is a crucial regulator in development and differentiation. We would like to investigate its function and regulation in adipogenesis. Knockdown of Trim 28 by transducing lentivirus-carrying shRNAs impairs the differentiation of 3T3-L1 preadipocytes, demonstrated by morphological observation and gene expression analysis. To understand the molecular mechanism of Trim28-mediated adipogenesis, the RNA-seq was performed to find out the possible Trim28-regulated genes. Dlk1 (delta-like homolog 1) was increased in Trim28 knockdown 3T3-L1 cells both untreated and induced to differentiation. Dlk1 is an imprinted gene and known as an inhibitor of adipogenesis. Further knockdown of Dlk1 in Trim28 knockdown 3T3-L1 would rescue cell differentiation. The epigenetic analysis showed that DNA methylation of Dlk1 promoter and differentially methylated regions (DMRs) was not altered significantly in Trim28 knockdown cells. However, compared to control cells, the histone methylation on the Dlk1 promoter was increased at H3K4 and decreased at H3K27 in Trim28 knockdown cells. Finally, we found Trim 28 might be recruited by transcription factor E2f1 to regulate Dlk1 expression. The results imply Trim28-Dlk1 axis is critical for adipogenesis.
\end{abstract}

Keywords: TRIM28; Dlk1; adipogenesis; DNA methylation; histone modification

\section{Introduction}

TRIM28 belongs to the tripartite motif family, containing N-terminal Ring finger, B boxes, and coiledcoil leucine zipper (RBCC) domain. RBCC is necessary for interaction with Krüppel-associated box (KRAB)containing zinc-finger proteins (ZFPs) to silence genes and form oligomers [1-4]. The mechanism of TRIM28-mediated gene repression is through the recruitment of histone deacetylase (HDAC) complex NuRD (nucleosome remodeling deacetylase) and histone H3 lysine 9-specific methyltransferase SETDB1 by C-terminal PHD and bromodomain [5,6]. The central PxVxL pentapeptide associates with heterochromatin protein 1 (HP1) [7]. KRAB-ZFPs and TRIM28 complex-mediated chromatin DNA recognition was accompanied by DNA methylation [8]. TRIM28 is a crucial regulator in development and differentiation. The knockout of Trim 28 gene results in embryonic lethality indicating that it plays 
an essential role in embryonic development [9]. It is required for the maintenance and pluripotency of embryonic stem cells $[10,11]$. Recent reports showed that TRIM28 haploinsufficiency in both mouse and human leads to lean and obese phenotypes arising from the identical genotypes through dysregulation of an imprinted gene network [12,13].

Adipogenesis was extensively studied by using mouse preadipocyte cell line 3T3-L1 [14]. 3T3-L1 preadipocytes were growth-arrested followed by adding differentiation inducers to trigger adipogenesis. Most studies focused on transcriptional regulation and a series of transcription activators and repressors were found to play functions in this process [15]. Recently, epigenetic regulation in adipogenesis was examined. Dynamic and distinct histone modifications were analyzed to understand the expression of key adipogenesis regulatory genes, indicating that H3K27 methyltransferase Ezh2 facilitates adipogenesis by repressing adipogenic inhibitors Wnt and Pref-1(preadipocyte factor-1) [16-18]. In addition, H3K9 methyltransferase G9a and SETDB1 inhibits adipogenesis but H3K4 demethylase LSD1 promotes adipogenesis through modifying PPAR $\gamma, \mathrm{C} / \mathrm{EBP} \alpha$, and Wnts promoters [19-23]. Inhibition of DNA methylation can also activate Wnt10a to suppress adipogenesis in 3T3-L1 cells [24]. Constitutive Dlk1(also named Pref-1) expression or the addition of a soluble form of Dlk1 inhibits 3T3-L1 adipocyte differentiation, while downregulation of Dlk1 by antisense expression enhances adipogenesis [25-30]. Dlk1 has been reported to be expressed from the paternal allele, but not from the maternal allele, which is controlled by DNA methylation on differentially methylated regions (DMRs) [31-33].

To explore the functional mechanism of TRIM28-mediated cellular differentiation, we knocked down Trim28 in 3T3-L1 preadipocytes. After RNA-seq analysis, the possible Trim28 targets were selected for further investigation. We found Trim 28 regulates Dlk1 expression through modulation of histone methylations.

\section{Results}

\subsection{Knockdown of Trim28 Impairs Adipogenesis}

To investigate the functional effect of Trim28 in adipogenesis, we knocked down Trim28 in 3T3-L1 preadipocytes by using Letivirus-carrying shRNAs. As shown in Figure 1a, both shRNAs decreased Trim 28 expression in mRNA and protein levels. The cells were induced to differentiation by FDMI (FBS, DEX, MIX and Insulin) treatment (see materials and methods). Oil red O staining showed knockdown (KD) of Trim 28 decreased lipid formation significantly (Figure 1b). Consistent with the phenotype, the mRNA levels of differentiation-related transcriptional factors and the adipocyte markers also were downregulated in Trim 28 KD cells (Figure 1c). In Figure 1d, cell numbers of Trim28 KD cells were decreased after induced to differentiation. The results indicate Trim28 plays a functional role during adipogenesis.

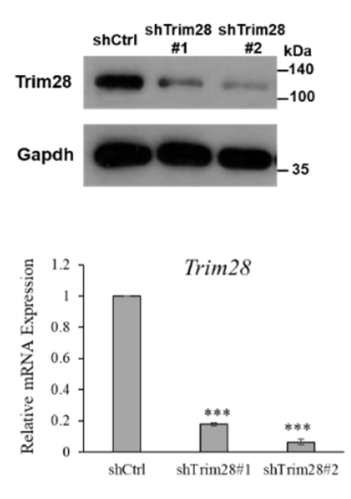

(a)

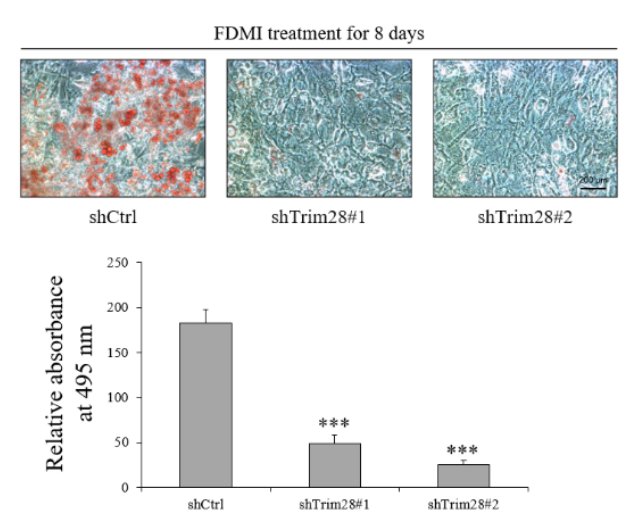

(b)

Figure 1. Cont. 


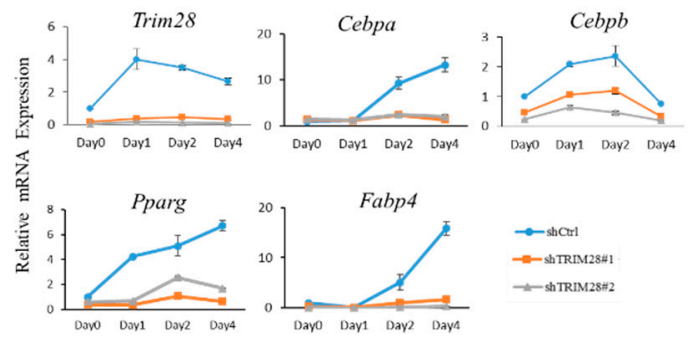

(c)

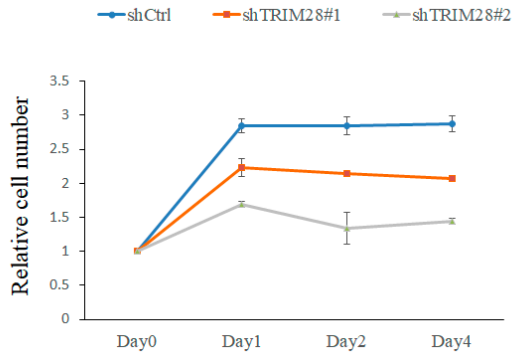

(d)

Figure 1. Trim 28 is required for differentiation of 3T3-L1 preadipocytes. (a) Protein and mRNA expression of Trim28 in knockdown 3T3-L1 preadipocytes. 3T3-L1 cells were transduced with lentiviralcarrying shRNA against Trim28 (shTrim28\#1 and shTrim28\#2) and a non-specific control (shCtrl). (b) The oil red O staining of control and Trim28 KD 3T3-L1 after FDMI (FBS, DEX, MIX and Insulin) treatment for differentiation of eight days. (c) mRNA expression of adipogenesis markers in Trim28 KD cells during treated with FDMI for zero, one, two, and four days. (d) 3T3-L1 cells treated with FDMI for zero, one, two, and four days. The cells were stained with trypan blue and the cell numbers were calculated by automated cell counter. The relative cell number was normalized with control cells at 0 day. ${ }^{* * *} p<0.001,{ }^{* *} p<0.01, * p<0.05$.

\subsection{RNA-Seq Analysis Identifies the Possible Targets of Trim28 in Adipogenesis}

To understand the molecular mechanism of Trim28-mediated adipogenesis, total RNAs were isolated from control and Trim $28 \mathrm{KD}$ cells without treatment or with inducing differentiation for two days for RNA-seq analysis. Downstream analyses include gene expression and deep analysis based on gene expression involving gene ontology (GO) enrichment analysis and Kyoto encyclopedia of genes and genomes (KEGG) pathway enrichment analysis. Pathway analysis of differentially expressed genes revealed that GO terms were associated with cell cycle, fibroblast proliferation, and chromatin silencing at day 0 , and fat cell differentiation, fibroblast proliferation, and cell cycle arrest at day 2 (Figure 2a, Table S1). These data indicated KD of Trim28 might reduce the proliferation of 3T3-L1, resulting in suppression of adipogenesis. In KEGG analysis, differentially expressed genes associated with cell cycle at day 0 were highly enriched in the upregulated gene set, and PPAR signaling pathway at day 2 were significantly downregulated in Trim $28 \mathrm{KD}$ cells (Figure 2b). The detailed genes in each pathway analysis were classified with upregulation and downregulation shown in Table S1. In Figure 2c, the expression levels of TRIM28, C/EBP $\alpha, \mathrm{C} / \mathrm{EBP} \beta, \mathrm{PPAR} \gamma$, and Fabp4 (Ap2) in fragments per kilobase of transcript per million mapped reads (FPKM) were similar with qPCR analysis in Figure 1c.

(a)

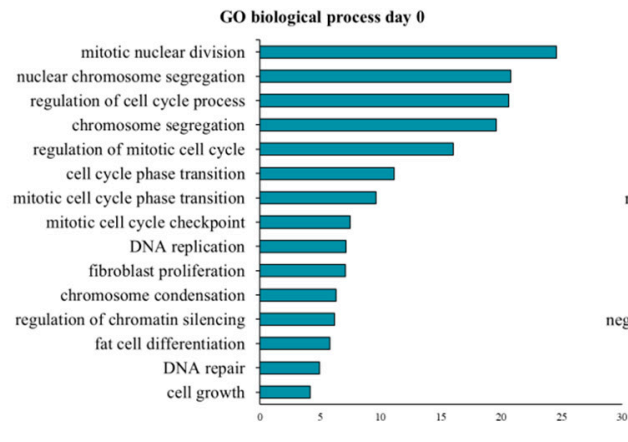

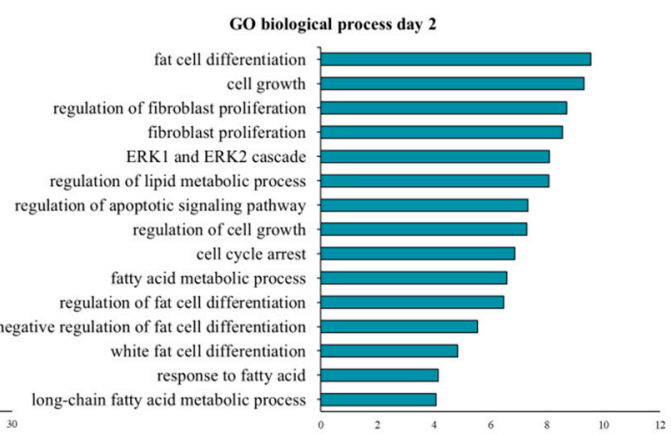

Figure 2. Cont. 

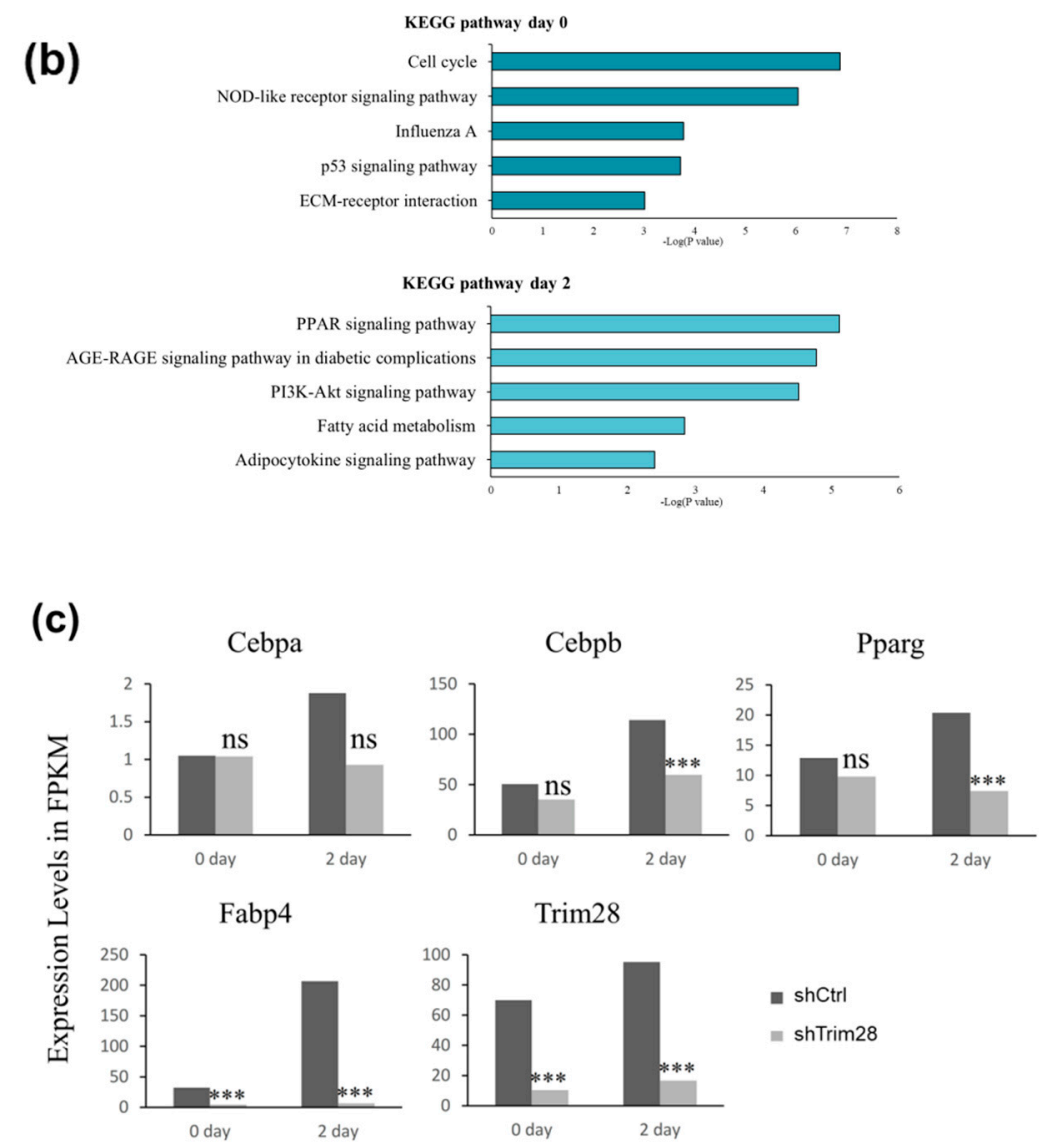

Figure 2. RNA-seq analysis in Trim28 KD 3T3-L1 cells. Genes were characterized as gene ontology (GO) biological processes (a) and Kyoto encyclopedia of genes and genomes (KEGG) pathway (b) in Trim28 knockdown (KD) vs. control cells at day 0 and day 2. (c) The expression level in FPKM (fragments per kilobase of transcript per million) of master regulators of adipocyte differentiation in Trim $28 \mathrm{KD}$ vs. control cells at day 0 and day 2 were shown. ${ }^{* * *} p<0.001$, ns: not significant.

\subsection{Dlk1 Is Upregulated in TRIM28 KD 3T3-L1 Preadipocyte}

Because TRIM28 is a corepressor and Trim28 KD in 3T3-L1 results in suppression of adipogenesis, we considered TRIM28 might regulate the expression of repressors instead of activators in 3T3-L1. In FPKM data, we found the expression levels of Dlk1 were significantly increased in FPKM at day 0 and day 2, and the relative mRNA levels during adipogenesis were also increased in Trim $28 \mathrm{KD}$ cells (Figure $3 \mathrm{a}, \mathrm{b}$ ). We further performed chromatin immunoprecipitation assay by using anti-Trim 28 to explore whether Trim28 targets to Dlk1 in 3T3-L1. In Figure 3c, TRIM28 directly binds to the Dlk1 promoter under non-induced condition (day 0 ).

\subsection{Knockdown of Dlk1 Rescues the Cell Differentiation in Trim28 KD Cells}

To examine whether TRIM28 regulates adipogenesis through suppression of Dlk1 expression, we created double-knockdown cells. The knockdown efficiency of Dlk1 and Trim 28 was confirmed by real-time PCR. The result indicated that the Dlk1 shRNA approximately decreased Dlk1 expression by $99 \%$ and $61 \%$ in single and double knockdown cells relative to the shCtrl control (Figure 4a, left). And Trim 28 was decreased by $90.8 \%$ and $66 \%$ in single and double knockdown cells (Figure 4a, right). The knockdown cells were triggered to differentiation, and the mRNA and protein expression levels of adipogenic transcription factor PPAR $\gamma$ were monitored by real-time PCR and western blot (Figure $4 b, c$ ). The expression of Pparg in preadipocytes is deficient, and induced in the second day of differentiation in shCtrl cells, whereas Trim28 KD suppressed its induction (Figure 4b). Knockdown of Dlk1 increased the mRNA levels of Pparg in day 0 and day 2 cells and it also restored the expression in Trim 28 KD 
cells (Figure 4b). Consistent with the mRNA expression, PPAR $\gamma$ protein expression exhibited a similar regulation in knockdown of Trim28 or/and Dlk1 cells (Figure 4c). Moreover, we used Oil red O staining to measure adipogenesis. As shown in Figure 4d, the cells were induced to differentiation for eight days, and Dlk1 KD cells enhanced the adipogenesis with 2-fold of cells population differentiating into lipid-rounded adipocytes relative to control. In contrast, the rounded-lipid filled adipocytes significantly declined in knockdown of Trim28. Interestingly, Dlk1 and Trim28 double KD cells significantly restored adipogenesis (Figure 4d). Taken together, the effect of Dlk1 knockdown suggests that Dlk1 is a crucial downstream factor in Trim28-regulated adipogenesis.

(a)

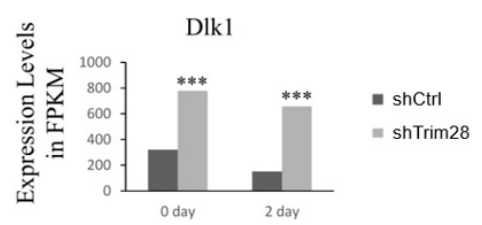

(b)

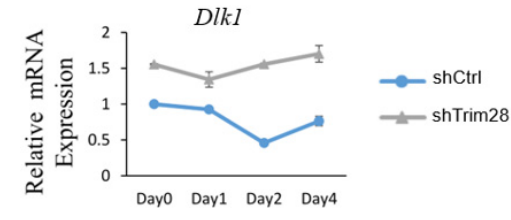

(c)
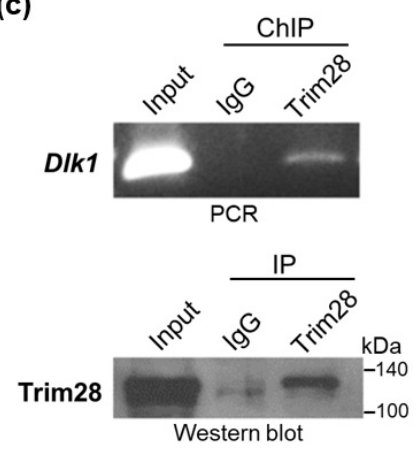

Figure 3. Knockdown of Trim 28 increases Dlk1 mRNA expression in 3T3-L1 cells. (a) Dlk1 expression level in RNA-seq at day 0 and day 2 in control and Trim28 KD 3T3-L1cells. ${ }^{* * *} p<0.001$. (b) The kinetic of Dlk1 mRNA expression during FDMI induction for differentiation in control and Trim28 KD 3T3-L1cells. (c) Chromatin-IP (ChIP)-qPCR. ChIP was performed in day 0 3T3-L1 cells by anti-Trim28 or control IgG. The precipitated genomic DNA was analyzed by semi-quantitative PCR with Dlk1 primers positioned at -481 to -341 bp upstream of the transcriptional start site (TSS). $1 \%$ volume of each cell lysate was analyzed by PCR to determine the input signals. The IP process was also monitored by western blot as shown in lower panel.

(a)

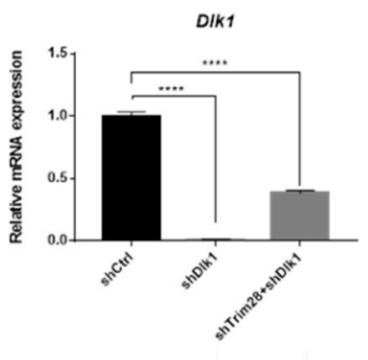

(b)

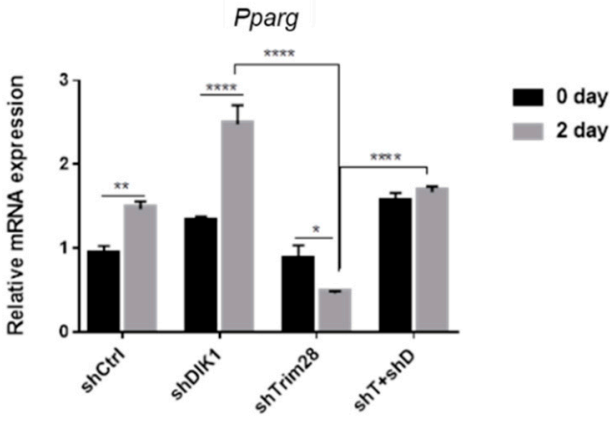

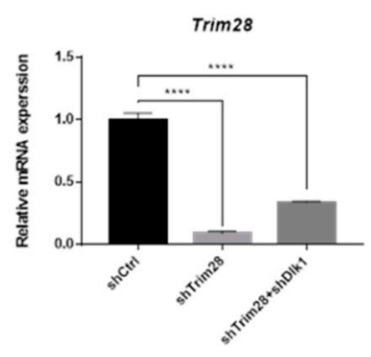

Figure 4. Cont. 
(c)

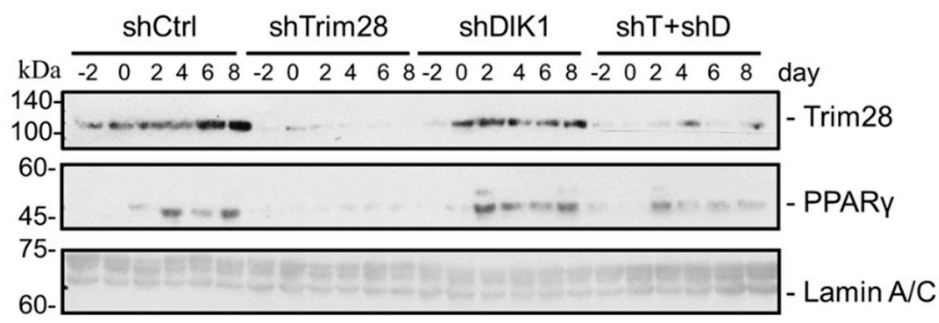

(d)
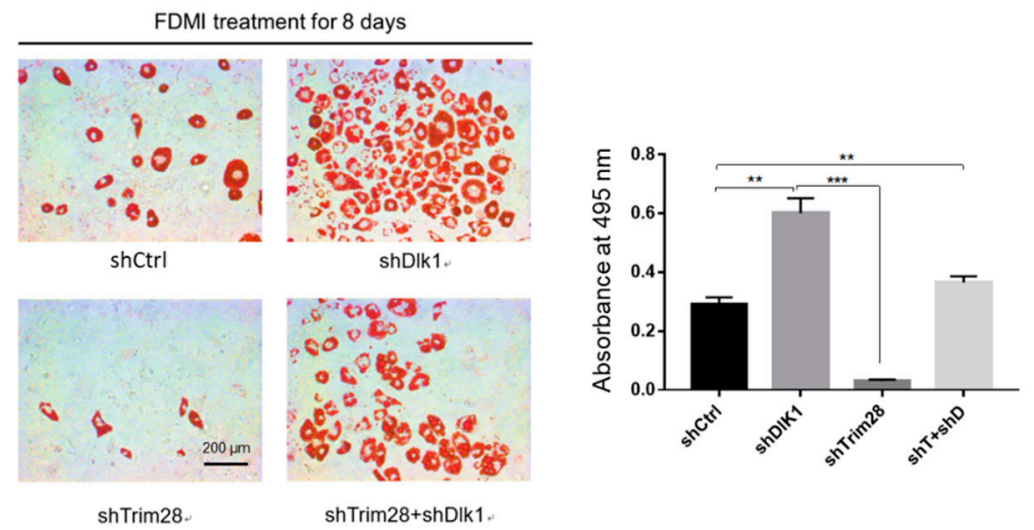

Figure 4. Knockdown of Dlk1 in Trim28 KD 3T3-L1 rescues cell differentiation. (a) Real-time PCR analysis of Dlk1 and Trim28 mRNA expression in 3T3-L1 cells transduced with lentiviral shRNA vectors for a standard control, Dlk1, Trim28, and Trim28+Dlk1. ${ }^{* * *} p<0.0001$ (b) Real-time PCR analysis of Pparg expression in 3T3-L1 cells as described in (a) after differentiation for zero days and two days. Quantitative PCR data were estimated by two-way ANOVA, ${ }^{* * * *} p<0.0001,{ }^{* *} p<0.01,{ }^{*} p<0.05$. (c) Western blot analysis of nuclear extracts from indicated 3T3-L1 cells induced differentiation for zero to eight days. The Trim 28 and PPAR $\gamma$ protein expression was detected. The expression of the 63-kDa Lamin C and 74-kDa Lamin A isoforms was used as a loading control. (d) Oil red O staining of the fat droplets on the indicated knockdown 3T3-L1 cells induced differentiation for eight days. Oil red $\mathrm{O}$ was dissolved in isopropanol consequently, and the content of dissolution was measured by spectrophotometer at OD $495 \mathrm{~nm}$. $p$ value was estimated by one-way ANOVA, ${ }^{* * *} p<0.001,{ }^{* *} p<0.01$.

\subsection{Epigenetic Analysis of Dlk1 Regulatory Regions}

Since TRIM28 is an epigenetic regulator, we examine the DNA methylation and histone modifications in the regulatory regions of $D l k 1$ gene during adipogenesis. First, we performed bisulfite sequencing to analyze DNA methylation. There are 50, 24, 32, and 27 CpG dyads in Dlk1 promoter, Dlk1-DMR, IG-DMR, and Gtl2-DMR, respectively (Figure 5a, Table S2). In Figure 5b, we compared the day 0 (no induction) and day 2 (FDMI induction) cells. The DNA methylated status of Dlk1 promoter was quite different from Dlk1-DMR, IG-DMR, and Gtl2-DMR, presenting in hypomethylated grade. Still, there are no significant differences in methylated quality between day 0 and day 2 cells at these regions after calculating methylated CpG numbers from 10-20 clones. However, the specific methylation sites at no.11 and no.20 CpG dyads in Dlk1 promoter were observed in two-day differentiated cells. Moreover, we analyzed the DNA methylation in Trim28 KD 3T3-L1 cells compared to shCtrl cells in day 0 (Figure 5c) and day 2 sections (Figure 5d). In day 0 cells, although IG-DMR and Dlk1 promoter presented slightly increased methylation in Trim $28 \mathrm{KD}$ cells compared to shCtrl cells, there are no significant differences after statistical analysis (Figure 5c, right panel). There are also no significant differences in four regulated regions among day 2 cells (Figure $5 \mathrm{~d}$, right panel). Taken together, the bisulfite sequencing analyses indicate that the DMRs of Dlk1-Gtl2 gene cluster are hypermethylated and Dlk1 promoter is hypomethylated. They were nearly not changed by knockdown of Trim 28 and differentiation. 
(a)

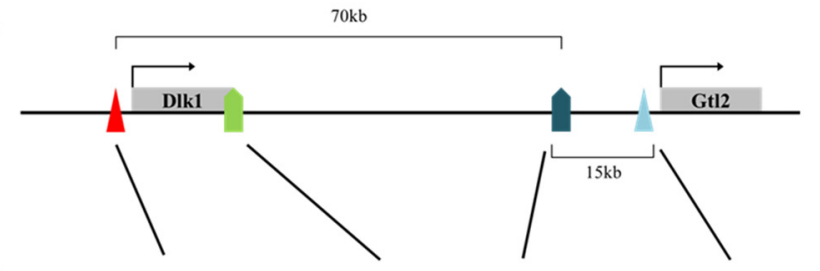

(b)

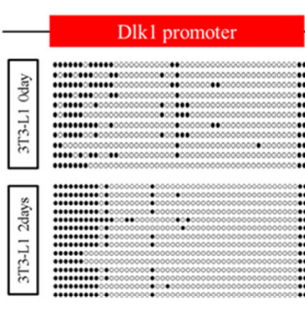

(c)
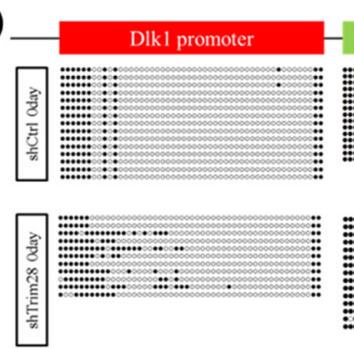

(d)

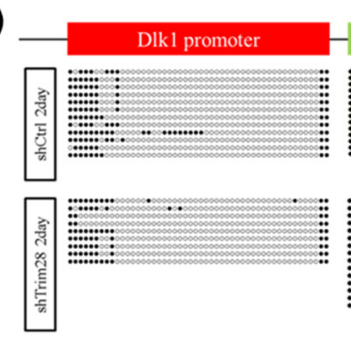

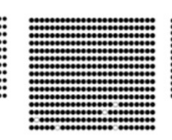
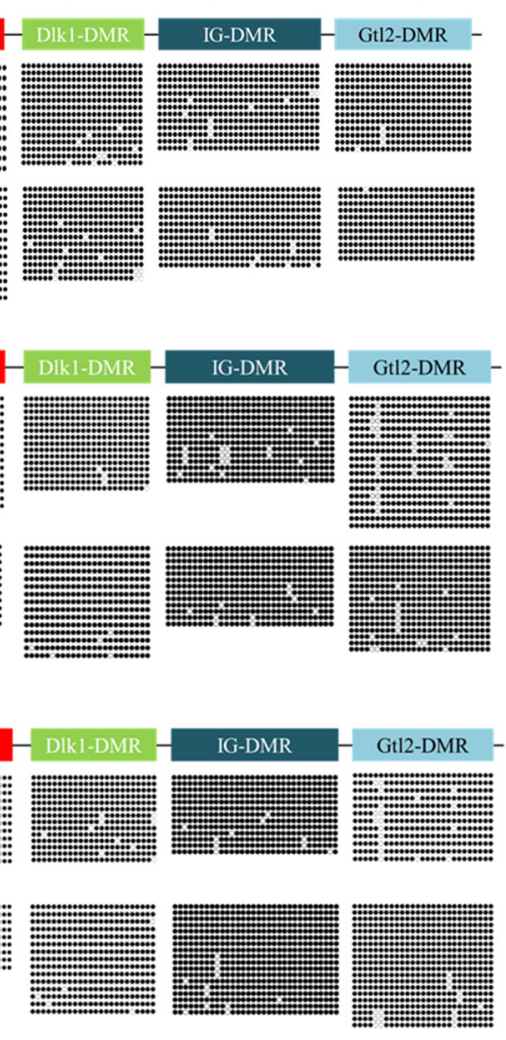

Gt12-DMR -
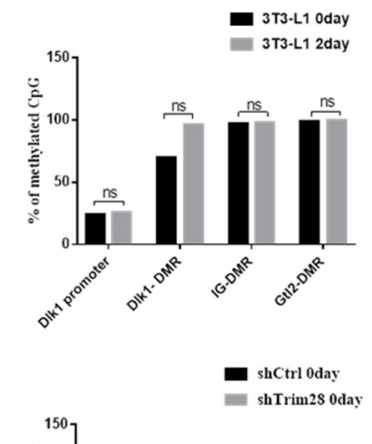

\section{H.}
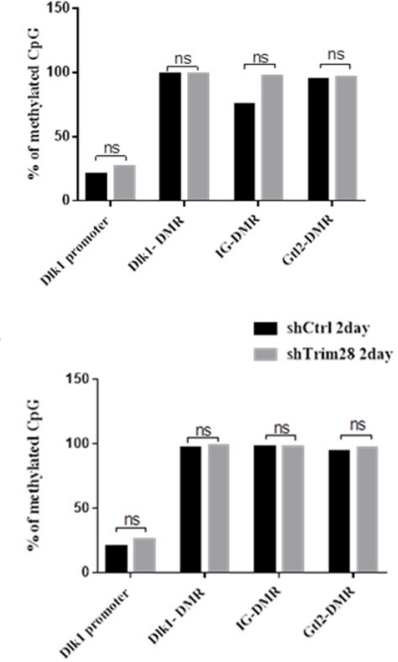

Figure 5. DNA methylation analysis on Dlk1 promoter and differentially methylated regions (DMRs) of Dlk1-Gtl2 gene cluster. (a) The schematic diagram of the Dlk1-Gtl2 gene cluster. The Dlk1 promoter, Dlk1-DMR, IG-DMR, and Gtl2-DMR were analyzed for DNA methylation. (b) Bisulfite sequencing of the day 0 and day 2 differentiated 3T3-L1 cells depicting the methylation status of each individual CpG island in these DMRs. The circle indicates a single CpG dyad; open circles represent unmethylated CpGs and filled represent methylated CpGs. Quantitative analysis of methylation status in total CpG dyads at Dlk1-Gtl2 DMRs via sanger sequencing. The data were estimated by two-way ANOVA, ns indicates not significant. (c) Bisulfite sequencing of day 0 undifferentiated Trim $28 \mathrm{KD}$ cells and shCtrl 3T3-L1 cells. (d) Bisulfite sequencing of day 2 differentiated Trim28 KD cells and shCtrl 3T3-L1 cells.

Next, the histone modifications were examined. Because $D l k 1$ expression in adipogenesis was reported to be repressed by Ezh2-mediated H3K27 methylation [18], we performed ChIP-qPCR to monitor the enrichment of $\mathrm{H} 3 \mathrm{~K} 27 \mathrm{me} 3$ on Dlk1 gene regulatory regions in shCtrl and Trim28 KD 3T3-L1 cells (Figure 6a). The active chromatin marker H3K4me3 was also observed (Figure 6b). Lower enriched levels of these two histone modifications on IG-DMR and Gtl2-DMR than on Dlk1 promoter were detected. Interestingly, on Dlk1 promoter we observed the high H3K27me3 enrichment and low H3K4me3 enrichment in shCtrl cells, and the opposite results were observed in Trim28 KD cells (Figure 6a,b). On IG-DMR, the H3K27me3 and H3K4me3 enrichments were increased in Trim28 KD cell. The results suggest that knockdown of Trim 28 can increase active chromatin marker H3K4me3 and decrease repressive chromatin marker H3K27me3 on Dlk1 promoter, leading to Dlk1 gene expression. 
(a)

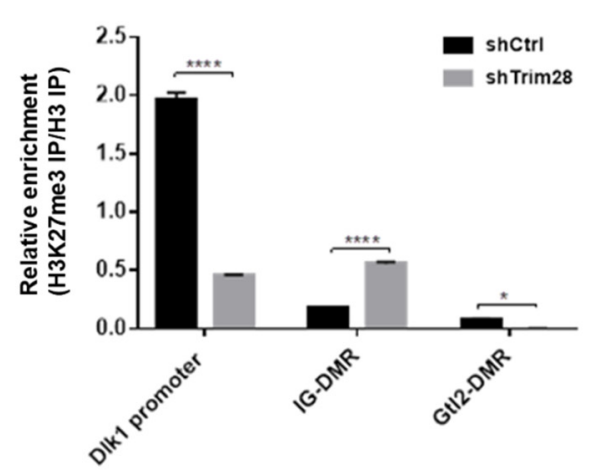

(b)

ChIP: H3K4me3

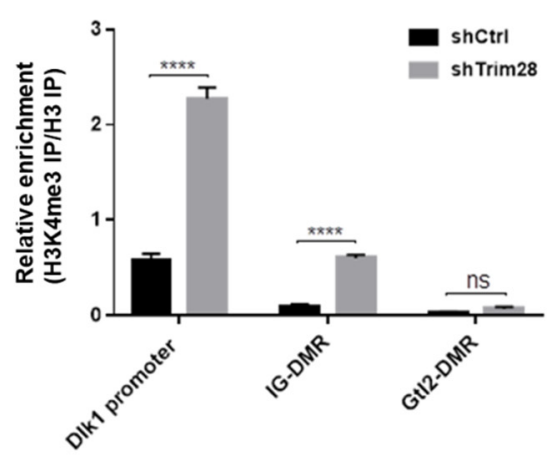

Figure 6. ChIP-qPCR analysis of Dlk1 promoter, IG-DMR and Gt12-DMR. ChIP was performed in control and Trim28 KD 3T3-L1 cells by antibodies against H3K27me3 (a) and H3K4me3 (b). The precipitated genomic DNA was analyzed by qPCR with primers as indicated. The sequences of qPCR primers for ChIP are listed in Table S3. The relative enrichment was shown by normalized with histone H3 IP. Data were representative of three replicate experiments. The data were estimated by two-way ANOVA, $* * * * p<0.0001,{ }^{*} p<0.05$, ns: not significant.

\subsection{Trim28 Interacts with E2f1 to Regulate Dlk1 Expression}

Because Trim28 is not a DNA-binding protein, we would like to know which protein recruits it to Dlk1 promoter. Previous studies indicated that Trim 28 associated with E2f1 and E2f1 bound to Dlk1 promoter $[34,35]$. Knockdown of E2f1 attenuated Dlk1 expression and increased Pparg expression at treated with FDMI for two days (Figure 7a). Immunoprecipitation performed by overexpression of Flag-E2f1 and HA-Trim28 in 293T cells demonstrated the interaction between Trim28 and E2f1 (Figure $7 \mathrm{~b}$ ). The luciferase reporter assay showed higher level of E2f1 can significantly activate the Dlk1 promoter and this activation is greater inhibited under overexpression of Trim28 (Figure 7c). The results show that Dlk1 expression is activated by E2f1 and repressed in the presence of Trim 28.

(a)

DIk1
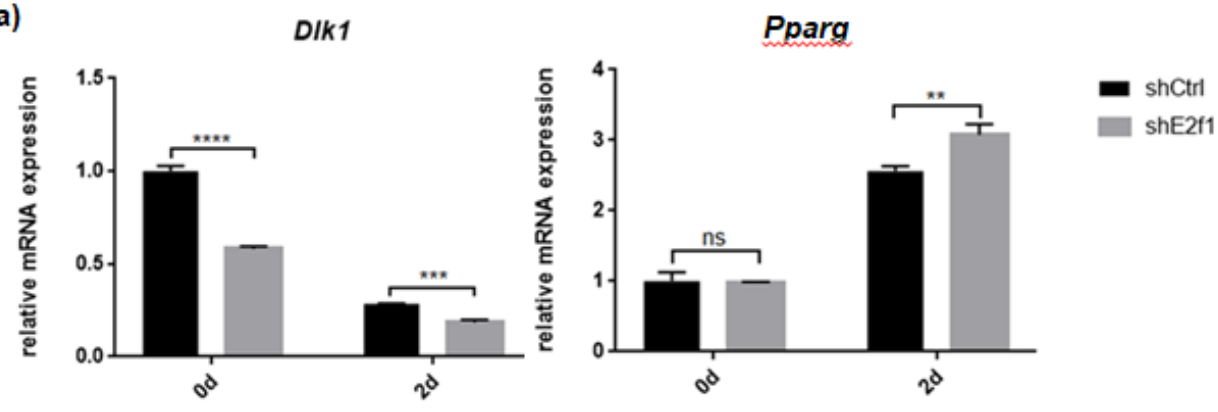

(b)

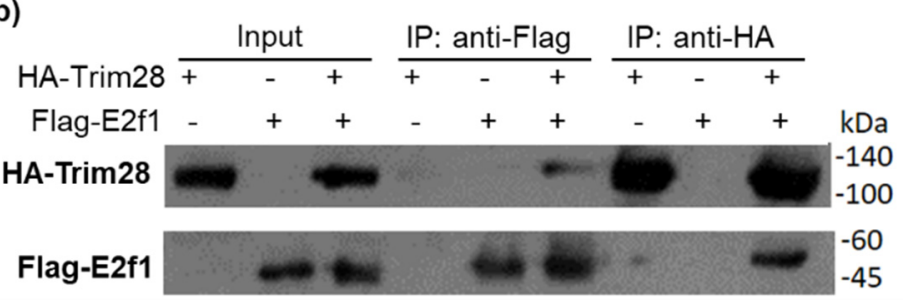

Figure 7. Cont. 
(c)

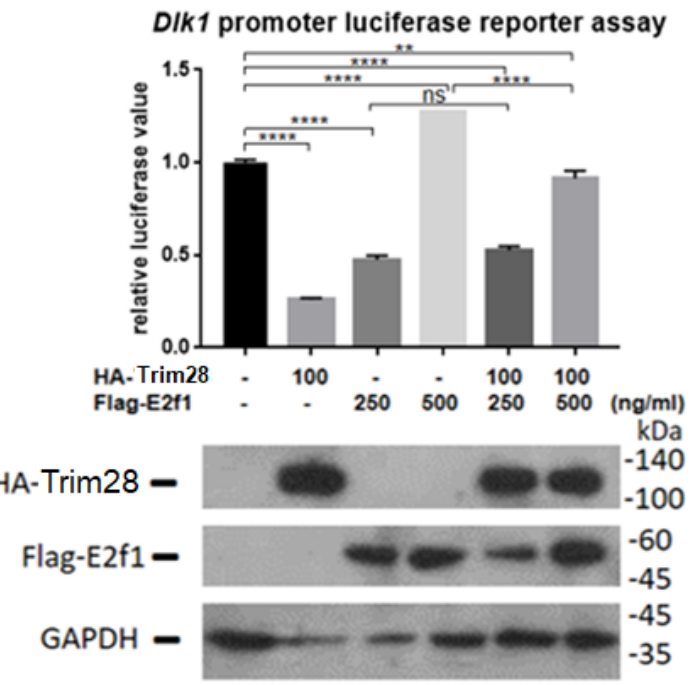

Figure 7. Trim 28 interacts with E2f1 to regulate Dlk1 expression. (a) Real-time PCR analysis of Dlk1 and Pparg expression in E2f1 KD 3T3-L1 cells after treated with FDMI for zero and two days. (b) Immunoprecipitation of Flag-E2f1 and HA-Trim 28 overexpressed in 293T cells. (c) Dlk1 promoter-driven luciferase assay. The plasmids were transfected into 293T cells as indicated and cell lysates were collected for luciferase assay. The lower panel showed the protein expression level. ${ }^{* * * *} p<0.0001,{ }^{* * *} p<0.001$, ** $p<0.01$, ns: not significant

\section{Discussion}

Our results provide evidence to support Trim28 KD impairs the differentiation of 3T3-L1 preadipocytes as previously described [36]. The RNA-seq analysis showed the effects of Trim 28 $\mathrm{KD}$ are mainly in the cell cycle on day 0 and in PPAR signaling pathway on day 2 . The knockdown of Trim28 leads to increasing the expression of cyclin A and cyclin B at day 0 (Table S1.1). It is consistent with previous study that TRIM28 can interact with HP1 to silence the expression of cyclin A2 [16]. When confluent 3T3-L1 preadipocytes are induced to differentiation, they will run two to three cell cycles named mitotic clonal expansion to increase cell numbers, which is required for adipogenesis [37]. Compared to control cells, the cell numbers of Trim $28 \mathrm{KD}$ are decreased (Figure 1d). This result indicates regulating mitotic clonal expansion is a role of Trim 28 to control adipogenesis.

In GO biological processes, different Wnt signaling pathways were upregulated at day 0 and day 2, respectively (Table S1.3 and S1.4). Wnt4 and Wnt5a, which are components of the non-canonical Wnt pathway, are upregulated in Trim $28 \mathrm{KO}$ cells on day 0 only, and they are known to function as positive regulators at initial stage of adipogenesis [38]. However, Wnt $10 \mathrm{~b}$ activating the $\mathrm{Wnt} / \beta$-catenin pathway and maintains preadipocytes phenotype by inhibiting expression of $\mathrm{C} / \mathrm{EBP} \alpha$ and PPAR $\gamma$ [39], was upregulated at day 2 only. It suggests that Trim $28 \mathrm{KD}$ might mediate Wnt10b expression to attenuate $\mathrm{C} / \mathrm{EBP} \alpha$ and PPAR $\gamma$ induction and further stop adipogenesis. Moreover, Setdb1, which is associated with chromatin silencing and fat cell differentiation, is significantly upregulated in Trim28 KD cells on day 0 and day 2 (Table S1.3 and S1.4). It was consistent with the previous report that Setdb1 inhibited adipogenesis by maintaining H3K9 methylation at the Cebpa and Pparg promoter [22]. Setdb1 was also activated by Wnt5a to suppress PPAR $\gamma$ expression and determine the fate of mesenchymal stem cells $[40,41]$. The results indicate that attenuating the differentiation of 3T3-L1 preadipocytes via Trim $28 \mathrm{KD}$ seems to be regulated by the cascades of repressors activation.

Dlk1 is one of the repressors activated in Trim28 KD 3T3-L1 cells at both day 0 and day 2. It was correlated with dysregulating imprinted gene networks under the haploinsufficiency of Trim28 [13]. The further knockdown of Dlk1 can rescue Trim28 KD-resulting inhibition of adipogenesis (Figure 4). Dlk1 is a transmembrane glycoprotein with an epidermal growth factor (EGF)-like repeats in the extracellular domain [42]. A soluble form of Dlk1 can be released by the TNF $\alpha$-converting enzyme 
to and then interact with either Notch or fibronectin to inhibit adipogenesis [43-45] through the activation of MEK/ERK signaling [46]. The Dlk1-Gtl2 cluster imprinted genes contain three paternally expressed protein-coding genes (Dlk1, Rtl1, and Dio3), multiple maternally expressed untranslated RNAs (including Gtl2), and three DMRs are methylated on the paternal allele [31,32,47-49]. In mouse embryos, Trim 28 can bind IG-DMR in a methylation-specific manner [50]. A recent study about human embryonic cells showed that knockout of TRIM28 resulted in lower DNA methylation at paternal DMR and led to increases of MEG3 (mouse Gtl2) RNAs [51]. Moreover, it was reported that knockdown of Trim28 increased the Dlk1 expression via DNA methylation alteration on IG-DMR and Gtl2-DMR in sheep embryonic fibroblasts [6]. Biallelic expression of DLK1 was also observed in some human embryonic cell lines due to hypo- or hyper-methylation at IG-DMR, indicating cell culture conditions might influence genomic imprinting [52]. However, our results showed no significant changes in DMR methylation in Trim28 KD 3T3-L1 preadipocytes, maintaining a high methylation status (Figure 5). On the other hand, knockdown of Trim 28 can increase gene activation marker H3K4me3 and decrease gene repression marker H3K27me3 on Dlk1 promoter (Figure 6). Thus, the results suggest that Trim28 might involve in epigenetic regulation of Dlk1 gene through histone modifications on Dlk1 promoter in 3T3-L1 preadipocytes.

It is well known that E2f1 is required for mitotic clonal expansion [53]. Its activity is controlled by associated retinoblastoma proteins and cell cycle regulators cyclins/CDKs [54,55]. How Trim28 modulates E2f1 protein complex to regulate the expression of target genes is unclear. Whether some of KRAB-ZFPs are involved in Trim28-mediated adipogenesis regulation will be investigated.

\section{Materials and Methods}

\subsection{Plasmid Constructs}

Flag-Trim28 expression plasmid was constructed as described [56], and the plasmid was digested by EcoRI/SalI, and the fragment was ligated to pCMV-HA-N vector (TaKaRa Bio, Kusatsu, Japan) for HA-Trim 28 expression. The Dlk1 promoter-driven luciferase reporter was constructed by subcloning the PCR product of nucleotides -1002 to +18 using primers: Forward CTGTCTGCATTTGACGGTGAAC and reverse CCGCCTTTTCGTACTGTC into pGL3-basic and sequences confirmed. The Myc-DDK-E2f1 was purchased from OriGene (Rockville, MD, USA).

\subsection{Cell Culture}

3T3-L1 preadipocytes were purchased from American Type Culture Collection (ATCC, CL-173) and cultured in Dulbecco's modified Eagle's medium (DMEM; Gibco, Waltham, MA, USA) supplemented with $10 \%$ newborn calf serum (NBCS; Gibco, Waltham, MA, USA), $100 \mathrm{U} / \mathrm{mL}$ penicillin, and $0.1 \mathrm{mg} / \mathrm{mL}$ streptomycin (Corning, Corning, NY, USA) at $37^{\circ} \mathrm{C}$ with $5 \% \mathrm{CO}_{2}$ in a humidified incubator. The density of 3T3-L1 cells were maintained about $60 \%$ confluent to keep the preadipocytes phenotype. To stimulate the differentiation of preadipocytes, two-day post-confluent3T3-L1 cells were treated with fresh medium containing $10 \%$ fetal bovine serum (FBS; HyClone, Logan, UT, USA) with hormonal cocktails including $5 \mu \mathrm{M}$ dexamethasone (DEX; Sigma-Aldrich, St. Louis, MO, USA), $0.5 \mathrm{mM}$ 3-isobutyl-1-methylxanthine (MIX, Sigma-Aldrich, St. Louis, MO, USA), and $5 \mu \mathrm{g} / \mathrm{mL}$ bovine insulin (Sigma-Aldrich, St. Louis, MO, USA). FDMI is short for FBS, DEX, MIX, and insulin. Human embryonic kidney 293T cells was cultured in DMEM (Gibco, Waltham, MA, USA) supplemented with 10\% fetal bovine serum (FBS, Hyclone, Logan, UT, USA), $100 \mathrm{U} / \mathrm{mL}$ penicillin, and $0.1 \mathrm{mg} / \mathrm{mL}$ streptomycin (Corning, Corning, NY, USA) at $37^{\circ} \mathrm{C}$ with $5 \% \mathrm{CO}_{2}$ in a humidified incubator.

\subsection{Oil Red O Staining}

After inducing differentiation for 8 days, 3T3-L1 were washed with PBS carefully and fixed with 3.7\% formaldehyde diluted in PBS at room temperature for $15 \mathrm{~min}$. Cells were incubated with filtered Oil red O (Sigma-Aldrich, St. Louis, MO, USA) at room temperature for $30 \mathrm{~min}$ and then washed 
four times by double-distilled water $\left(\mathrm{ddH}_{2} \mathrm{O}\right)$. Stained cells were photographed by the microscope (Carl Zeiss Axiovert S100, Oberkochen, Germany) connected to the computer software. After that, Oil Red O was dissolved in $1 \mathrm{~mL}$ of $100 \%$ isopropanol and incubated at room temperature for $5 \mathrm{~min}$. The triglyceride content was measured by spectrophotometer at OD $495 \mathrm{~nm}$. The relative values were normalized with the control sample.

\subsection{Nuclear Extracts Preparation and Western Blot}

To prepare nuclear extracts, $5 \times 10^{6} 3 \mathrm{~T} 3$-L1 cells were resuspended in $400 \mu \mathrm{L}$ of buffer A (10 mM HEPES pH7.9, $10 \mathrm{mM} \mathrm{KCl}, 1.5 \mathrm{mM} \mathrm{MgCl}_{2}, 1 \mathrm{mM}$ DTT, and protease inhibitors). The cell suspension was on ice for $15 \mathrm{~min}$, and then $25 \mu \mathrm{L}$ of $10 \% \mathrm{NP}-40$ was added followed by vortexing for $10 \mathrm{~s}$. After centrifugation at $10,000 \times g$ for $30 \mathrm{~s}$, the supernatant was collected as cytoplasmic extract. The nuclear pellets were resuspended in $100 \mu \mathrm{L}$ of buffer C (20 mM HEPES pH7.9, $400 \mathrm{mM} \mathrm{NaCl}, 1 \mathrm{mM}$ EDTA, $1 \mathrm{mM}$ EGTA, $1 \mathrm{mM}$ DTT, and protease inhibitors) and rocked on ice for $20 \mathrm{~min}$. After centrifugation at top speed for $10 \mathrm{~min}$, the supernatant was collected as nuclear extract. Protein concentration was quantified by Bradford method (Bio-Rad, protein assay kit). Four-fold sample buffer ( $200 \mathrm{mM}$ Tris $\mathrm{pH} 6.8,8 \% \mathrm{SDS}, 0.4 \%$ bromophenol blue, $40 \%$ glycerol, $400 \mathrm{mM} \beta$-mercaptoethanol) was added to protein samples and samples were boiled at $100{ }^{\circ} \mathrm{C}$ for $5 \mathrm{~min}$. The denatured proteins were subjected to sodium dodecyl sulfate polyacrylamide gel electrophoresis (SDS-PAGE) and transferred to $0.45 \mu \mathrm{m}$-pore-size polyvinylidene fluoride (PVDF) membranes (Millipores) by semi-dry transfer machine (Hoefer, Holliston, MA, USA). After blocking with 5\% skim milk, membranes were probed with indicated primary antibodies (anti-TRIM28 from Biolegend (San Diego, CA, USA); anti-PPAR $\gamma$ and anti-Lamin A/C from Santa Cruz Biotechnology (Dallas, TX, USA); anti-HA from Bethyl (Montgonery, TX, USA); anti-Flag from Sigma-Aldrich (St. Louis, MO, USA)) for two hours at room temperature or at $4{ }^{\circ} \mathrm{C}$ for overnight. Membranes were washed with PBST (0.1\% Tween-20 in PBS) for $10 \mathrm{~min}$ three times and then incubated with secondary antibodies conjugated horseradish peroxidase (KPL) for one hour at room temperature. Then membranes were washed with PBST for $10 \mathrm{~min}$ three times, and unbound antibodies were removed with the wash step. Western Lightening Plus Enhanced Chemiluminescence reagent (Perkin Elmer, Waltham, MA, USA) was added to membranes and the emission luminescence was exposed to X-ray film (Fujifilm, Tokyo, Japan).

\subsection{Dual Luciferase Reporter Assay}

After seeding the 293T cells in 12-well about 30-40\% confluent $\left(1 \times 10^{5}\right.$ cells $)$ with $1 \mathrm{~mL}$ medium for overnight, the calcium phosphate precipitation transfection was conducted. Every well was transfected with $0.7 \mu \mathrm{g}$ DNA (contain desired plasmids and pCMV-Renilla Luc as an internal control) in $100 \mu \mathrm{L}$. Cells were harvested after $24 \mathrm{~h}$, and lysed in $25 \mu \mathrm{L}$ of passive lysis buffer (Promega, Madison, WI, USA). The cell lysates were subjected to dual luciferase reporter assays following the manufacturer's protocol (Promega, Madison, WI, USA). After subsequently adding substrates, the firefly luciferase activities and Renilla luciferase activities were measured by luminometer (Packard, Downer Grove, IL, USA). The firefly luciferase activities were normalized to Renilla luciferase activities. The relative luciferase activities represented that the luciferase activities of reporter carrying $D l k 1$ promoter were normalized to the reporter only. Each treatment group contained triplicates, and each experiment was repeated at least three times.

\subsection{Whole Cell Extracts Preparation and Immunoprecipitation Assay}

293T cells had been seeded in 6-cm dishes for one day before transfection, and transfected with indicated plasmids using calcium phosphate precipitation method. Cells were washed one time with PBS and lysed with WCE buffer (25 mM HEPES pH 7.5, $300 \mathrm{mM} \mathrm{NaCl}, 1.5 \mathrm{mM} \mathrm{MgCl} 2,0.2 \mathrm{mM}$ EDTA, $0.1 \%$ Triton X-100, $1 \mathrm{mM}$ DTT, and protease inhibitors). The cell lysates were shaken at $4{ }^{\circ} \mathrm{C}$ for $30 \mathrm{~min}$ and centrifuged at $12,000 \mathrm{rpm}, 4^{\circ} \mathrm{C}$ for $5 \mathrm{~min}$. The cell extracts were pre-cleared by using protein $\mathrm{G}$ agarose (Sigma-Aldrich, St. Louis, MO, USA) for $1 \mathrm{~h}$ at $4{ }^{\circ} \mathrm{C}$ and immunoprecipitated by using anti-Flag 
M2 agarose (Sigma-Aldrich, St. Louis, MO, USA ) or anti-HA agarose (Sigma-Aldrich, St. Louis, MO, USA) for $2 \mathrm{~h}$ at $4{ }^{\circ} \mathrm{C}$. Unbound proteins were removed by washing with WCE buffer three times and diluted protein sample buffers were added. Samples were boiled at $100{ }^{\circ} \mathrm{C}$ for $5 \mathrm{~min}$ and subjected to western blot analysis.

\subsection{Lentivirus Production and Infection of 3T3-L1 Cells}

Lentiviral vector-mediated shRNA technology was used to knock down the Trim 28 and $D l k 1$ genes. Two mouse Trim 28 short hairpin RNAs (shRNA) target sequences \#1:AGACATCGTGGAGAATTATTT (TRCN0000304660), \#2: GGACTACAATCTGATTGTTAT (TRCN0000304607), Dlk1 shRNA CCATCGTC TTTCTCAACAAGT (TRCN0000095446), E2f1 shRNA CTCACTCCTGGAGCATGTTAA (TRCN0000374127) and scrambled control pLKO.1-shLuc (TRCN0000072243) were obtained from the National RNAi Core Facility at the Academia Sinica, Taipei, Taiwan. Viruses were produced by using calcium phosphate precipitation transfection. Fourteen micrograms of pPGK-GFP or pLKO.1-shLuc or -shTrim28 and shDlk1 constructs with $14 \mu \mathrm{g}$ of pCMV $\Delta$ R8.91 and $2 \mu \mathrm{g}$ of pMD.G were co-transfected in early subculture of $293 \mathrm{~T}$ cells. After eight hours, the medium was replaced with 3T3-L1 maintain medium to collect virus. Then, 3T3-L1 cells in 6-well plate were infected with the viral supernatants in the presence of $8 \mu \mathrm{g} / \mathrm{mL}$ of polybrene for $48 \mathrm{~h}$ and further selected with $3 \mu \mathrm{g} / \mathrm{mL}$ puromycin for one week. The whole cell extracts and total RNA were extracted for knockdown efficiency examination by western blotting and real-time PCR, respectively.

\subsection{DNA Methylation Analysis}

Genomic DNA samples were harvested and subjected to bisulfite mutagenesis with the EpiTect Fast DNA Bisulfite kit (Qiagen). After the bisulfite treatment, genomic DNA was purified and amplified by nested PCR with the primers corresponding to the imprinted DMR regions and the Dlk1 promoter (Table S3). All PCR conditions were $94{ }^{\circ} \mathrm{C}$ for $30 \mathrm{~s}, 52^{\circ} \mathrm{C}$ for $1 \mathrm{~min}$, and $72{ }^{\circ} \mathrm{C}$ for $1 \mathrm{~min}$ for 30 cycles in the first PCR and 35 cycles in the second PCR $[57,58]$. The second PCR products were subcloned into pCRII-TOPO TA vector. Fifteen to 20 clones of each construct were selected to sequence. The CPG islands when unmethylated were sensitive to bisulfite mutagenesis, but the sequences were preserved if these $\mathrm{CpG}$ islands were methylated.

\subsection{RNA Extraction and Reverse Transcription}

Cells in 6-cm dish were washed with PBS and lysed with $1 \mathrm{~mL}$ TRIzol reagent (ThermoFisher, Waltham, MA, USA). After incubated for $5 \mathrm{~min}$ at room temperature, the homogenized samples were added with $200 \mu \mathrm{L}$ of chloroform and shaken for $15 \mathrm{~s}$. The samples were incubated at room temperature for $3 \mathrm{~min}$ and then centrifuged at 13,000 rpm for $15 \mathrm{~min}$ at $4{ }^{\circ} \mathrm{C}$. The upper aqueous phase containing RNA was collected into new vials and mixed with equal volume of isopropanol. After incubation at room temperature for $10 \mathrm{~min}$, the mixtures were centrifuged at $13,000 \mathrm{rpm}$ for $10 \mathrm{~min}$ at $4{ }^{\circ} \mathrm{C}$ to precipitate RNA. The supernatant was discarded and the RNA pellets were washede twice by $100 \%$ ethanol, and once by $75 \%$ ethanol. Then, the RNA pellets were air-dried for $30 \mathrm{~min}$. RNA was dissolved with $10 \mu \mathrm{L}$ of DEPC $\mathrm{H}_{2} \mathrm{O}$. After quantification by A 260/280 measurements, $2 \mu \mathrm{g}$ RNA was annealed with $0.5 \mu \mathrm{g}$ oligo $\mathrm{dT}$ at $70{ }^{\circ} \mathrm{C}$ for $10 \mathrm{~min}$ and then reverse transcribed into cDNA using M-MLV reverse transcriptase (Promega, Madison, MA, USA) following the manufacturer's instructions.

\subsection{Real-Time PCR}

Quantitative real-time PCR was performed with the Applied Biosystems 7300 Real-Time PCR System (Applied Biosystems, Foster City, CA, USA). The total volume was $20 \mu \mathrm{L}$ including Faststart Universal SYBR Green Master (Roche, Basel, Switzerland), 20-folds diluted cDNA, and $0.3 \mu \mathrm{M}$ forward and reverse primers as shown in Table S3. The amplification conditions were 40 cycles of $95^{\circ} \mathrm{C}$ for $15 \mathrm{~s}$ and $60^{\circ} \mathrm{C}$ for $1 \mathrm{~min}$. The results were analyzed by $2^{-\Delta \Delta \mathrm{Ct}}$ relative quantitation method. 


\subsection{RNA Sequencing (Quantification)}

RNA samples were prepared according to the RNA extraction protocol. All subsequent technical procedures including mRNA purification and fragment, cDNA synthesis, A-tailing and adapter ligation, PCR amplification, and Illumina sequencing were performed digital gene expression (DGE) at Genomics (Taipei, Taiwan) by using Illumina NextSeq 500 sequencing system. The resulting reads were aligned to mouse reference genome GRCm38 using Bowtie 2 [59], and the numbers of sequencing reads mapped to each gene in the reference were tabulated. Referring to the significance of digital gene expression profiles, a strict algorithm was developed by Genomics company to identify differentially expressed genes (DEGs) between two samples. The DEGs were displayed in Tables S4 and S5.

\subsection{Chromatin Immunoprecipitation Assay}

3T3-L1 cells were seeded in 10-cm dishes with $100 \%$ confluent. Until reaching differentiation condition, cells were crosslinked with $1 \%$ formaldehyde in medium at $37^{\circ} \mathrm{C}$ for $10 \mathrm{~min}$. The final concentration of $125 \mathrm{mM}$ glycine was added to quench unreacted formaldehyde for $5 \mathrm{~min}$. The medium was and cells were washed with $5 \mathrm{~mL}$ cold PBS three times or more to remove as much triglyceride as possible. Cells were lysed in $300 \mu \mathrm{L}$ of lysis buffer containing protease inhibitor cocktail (Sigma-Aldrich, St. Louis, MO, USA) on ice for $15 \mathrm{~min}$, and the cell suspension was vortexed briefly every $5 \mathrm{~min}$. The nuclei were collected by centrifugation at $9000 \times \mathrm{g}$ for $5 \mathrm{~min}$ at $4{ }^{\circ} \mathrm{C}$ and re-suspended with $160 \mu \mathrm{L}$ nuclear lysis buffer containing protease inhibitorson ice for $10 \mathrm{~min}$. The nuclear lysates were sonicated on ice with water at middle strength, sonicating $30 \mathrm{~s}$ and stopping $30 \mathrm{~s}$, for 30-60 min. Two microliters of sheared chromatin was resolved by electrophoresis through the $2 \%$ agarose gel to check the length of DNA fragments between $200-600 \mathrm{bp}$, and centrifugated at 12,000 $\times g$ for $5 \mathrm{~min}$ at 4 ${ }^{\circ} \mathrm{C}$. The supernatant was collected and diluted 10 -fold with dilution buffer $(20 \mathrm{mM}$ Tris- $\mathrm{HCl} \mathrm{pH} 8.1$, $167 \mathrm{mM} \mathrm{NaCl}, 0.01 \%$ SDS, $1 \%$ Triton X-100, 1 mM EDTA) containing protease inhibitors. The soluble chromatin complexes were separated into two parts for IP with pre-immune serum and anti-TRIM28, respectively, and took $1 \%$ of the chromatin as input preserved at $4{ }^{\circ} \mathrm{C}$. Then, the samples were incubated with protein $\mathrm{A} / \mathrm{G}$ magnetic beads overnight after the immunoprecipitating antibodies were conjunct with $20 \mu \mathrm{L}$ magnetic protein A/G beads for two hours. The antibodies include anti-KAP1 (abcam, ab10483), anti-H3 (abcam, ab1791), anti-H3K4me3 (abcam, ab8580), and anti-H3K27me3 (abcam, ab6002). The beads were washed with $0.5 \mathrm{~mL}$ of each following buffers: Low salt wash buffer $(0.1 \%$ SDS, $1 \%$ Triton X-100, $2 \mathrm{mM}$ EDTA, $20 \mathrm{mM}$ Tris- $\mathrm{HCl} \mathrm{pH} \mathrm{8.1,} 150 \mathrm{mM} \mathrm{NaCl}$ ) once, high salt wash buffer (0.1\% SDS, 1\% Triton X-100, 2 mM EDTA, 20 mM Tris-HCl, pH 8.1, $500 \mathrm{mM} \mathrm{NaCl}$ ) once, LiCl wash buffer (0.25M LiCl, 1\% IGEPAL CA630, 1\% deoxycholic acid (sodium salt), 1 mM EDTA, $10 \mathrm{mM}$ Tris $\mathrm{pH}$ 8.1) once, and TE buffer (10 mM Tris-HCl pH 8.0, 1 mM EDTA) once. Each wash step was incubated for $5 \mathrm{~min}$ on rotating platform at $4{ }^{\circ} \mathrm{C}$. Chromatin complexes were eluted with $100 \mu \mathrm{L}$ elution buffer $\left(1 \% \mathrm{SDS}, 0.1 \mathrm{M} \mathrm{NaHCO}_{3}\right)$ containing $1 \mu \mathrm{L}$ proteinase $\mathrm{K}$ for $2 \mathrm{~h}$ at $62{ }^{\circ} \mathrm{C}$ with vortex, and then incubated at $95{ }^{\circ} \mathrm{C}$ for $10 \mathrm{~min}$ to de-crosslink the chromatin complexes. The samples were cooled down to room temperature, and the supernatant was transferred to the new tube. DNA purification steps were followed in the manufacturer's protocol by using the Magna ChIP ${ }^{\mathrm{TM}} \mathrm{A} / \mathrm{G}$ kit (Millipore, Burlington, MA, USA). The DNA was analyzed by quantitative real-time PCR followed by the previous steps. The forward and reverse primers were: Dlk1-F: GTGGTTTTCGTGTGTGCATC and Dlk1-R: AACGCTCACAGACACAGTAAG; IG-DMR-F: GGAAGACAAAGAGCAAGCCTGT and IG-DMR-R: CTAGACCAACGGTGAGCCAGGAT; Gtl2-DMR-F: CAAGATAGTCCGTCAGAATCGGGG and Gtl2-DMR-R: GGGCGATTTGTAGACAGAAACTGG [60].

\subsection{Statistical Analysis}

The results were presented as the mean \pm standard deviation (SD) of at least three independent experiments. The statistically significant values were calculated by one-tailed student's $t$-test, shown in 
Figures 1-3, by 1-way or 2-way ANOVA analysis, shown in Figures 4-6. The significance was labeled as ${ }^{*} p<0.05,{ }^{* *} p<0.01,{ }^{* * *} p<0.001,{ }^{* * * *} p<0.0001$ or ns, not significant.

\section{Conclusions}

Knockdown of Trim28 in 3T3-L1 preadipocytes activates several repressors in adipogenesis including Wnt proteins and Dlk1, leading to differentiation inhibition. Dlk1 activation in Trim28 KD cells is correlated with histone modifications of Dlk1 promoter but not with DNA methylation in DMRs.

Supplementary Materials: Supplementary materials can be found at http://www.mdpi.com/1422-0067/21/19/7245/ s1, Table S1.1 Pathway analysis with Trim28 KD vs. control 3T3-L1 at day 0 by using KEGG pathway database, Table S1.2 Pathway analysis with Trim28 KD vs. control 3T3-L1 at day 2 by using KEGG pathway database, Table S1.3 Bioinformatics analysis with Trim28 KD vs. control 3T3-L1 at day 0 by using GO database, Table S1. 4 Bioinformatics analysis with Trim 28 KD vs. control 3T3-L1 at day 2 by using GO database, Table S2. Sequences of CpG dyads at Dlk1-Gtl2 locus, Table S3. Primers for real-time PCR, Table S4. The differentially expressed genes of shTrim 28 vs. shCtrl on day 0, Table S5. The differentially expressed genes of shTrim 28 vs. shCtrl on day 2.

Author Contributions: Conceptualization, C.-J.C.; methodology, H.-P.L., C.-J.L., and W.-C.C.; validation, W.-C.C.; formal analysis, H.-P.L., C.-J.L., and Y.-J.C.; investigation, H.-P.L., C.-J.L., and S.-W.L.; resources, H.-H.W.; data curation, H.-P.L. and Y.-J.C.; writing-original draft preparation, H.-P.L., C.-J.L., and W.-C.C.; writing-review and editing, C.-J.C.; visualization, C.-J.C.; supervision, C.-J.C.; project administration, C.-J.C.; funding acquisition, H.-H.W. and C.-J.C. All authors have read and agreed to the published version of the manuscript.

Funding: This research was funded by Academia Sinica in Taiwan, grant 034004 (to CJC), Ministry of Science and Technology grants 107-2314-B-075-036 and 108-2314-B-075-043-MY2 (to HHW), and Taipei Veterans General Hospital Grants V105C-179, V106C-180 and V107C-176 (to HHW).

Acknowledgments: We thank the National RNAi Core Facility at Academia Sinica in Taiwan for providing shRNA reagents and related services; Yixuan Yang for manuscript revision.

Conflicts of Interest: The authors declare no conflict of interest.

\section{References}

1. Friedman, J.R.; Fredericks, W.J.; Jensen, D.E.; Speicher, D.W.; Huang, X.P.; Neilson, E.G.; Rauscher, F.J. KAP-1, a novel corepressor for the highly conserved KRAB repression domain. Genes Dev. 1996, 10, 2067-2078. [CrossRef] [PubMed]

2. Peng, H.; Begg, G.E.; Schultz, D.C.; Friedman, J.R.; Jensen, D.E.; Speicher, D.W.; Rauscher, F.J. Reconstitution of the KRAB-KAP-1 repressor complex: A model system for defining the molecular anatomy of RING-B box-coiled-coil domain-mediated protein-protein interactions. J. Mol. Biol. 2000, 295, 1139-1162. [CrossRef] [PubMed]

3. Sun, Y.; Keown, J.R.; Black, M.M.; Raclot, C.; Demarais, N.; Trono, D.; Turelli, P.; Goldstone, D.C. A Dissection of Oligomerization by the TRIM28 Tripartite Motif and the Interaction with Members of the Krab-ZFP Family. J. Mol. Biol. 2019, 431, 2511-2527. [CrossRef] [PubMed]

4. Stoll, G.A.; Oda, S.I.; Chong, Z.S.; Yu, M.; McLaughlin, S.H.; Modis, Y. Structure of KAP1 tripartite motif identifies molecular interfaces required for retroelement silencing. Proc. Natl. Acad. Sci. USA 2019, 116, 15042-15051. [CrossRef]

5. Schultz, D.C.; Friedman, J.R.; Rauscher, F.J. Targeting histone deacetylase complexes via KRAB-zinc finger proteins: The PHD and bromodomains of KAP-1 form a cooperative unit that recruits a novel isoform of the Mi-2alpha subunit of NuRD. Genes Dev. 2001, 15, 428-443. [CrossRef]

6. Schultz, D.C.; Ayyanathan, K.; Negorev, D.; Maul, G.G.; Rauscher, F.J. SETDB1: A novel KAP-1-associated histone $\mathrm{H} 3$, lysine 9-specific methyltransferase that contributes to HP1-mediated silencing of euchromatic genes by KRAB zinc-finger proteins. Genes Dev. 2002, 16, 919-932. [CrossRef]

7. Ryan, R.F.; Schultz, D.C.; Ayyanathan, K.; Singh, P.B.; Friedman, J.R.; Fredericks, W.J.; Rauscher, F.J. KAP-1 corepressor protein interacts and colocalizes with heterochromatic and euchromatic HP1 proteins: A potential role for Kruppel-associated box-zinc finger proteins in heterochromatin-mediated gene silencing. Mol. Cell. Biol. 1999, 19, 4366-4378. [CrossRef]

8. Quenneville, S.; Turelli, P.; Bojkowska, K.; Raclot, C.; Offner, S.; Kapopoulou, A.; Trono, D. The KRAB-ZFP/ KAP1 system contributes to the early embryonic establishment of site-specific DNA methylation patterns maintained during development. Cell Rep. 2012, 2, 766-773. [CrossRef] 
9. Cammas, F.; Mark, M.; Dolle, P.; Dierich, A.; Chambon, P.; Losson, R. Mice lacking the transcriptional corepressor TIF1beta are defective in early postimplantation development. Development 2000, 127, 2955-2963.

10. Hu, G.; Kim, J.; Xu, Q.; Leng, Y.; Orkin, S.H.; Elledge, S.J. A genome-wide RNAi screen identifies a new transcriptional module required for self-renewal. Genes Dev. 2009, 23, 837-848. [CrossRef]

11. Seki, Y.; Kurisaki, A.; Watanabe-Susaki, K.; Nakajima, Y.; Nakanishi, M.; Arai, Y.; Shiota, K.; Sugino, H.; Asashima, M. TIF1beta regulates the pluripotency of embryonic stem cells in a phosphorylation-dependent manner. Proc. Natl. Acad. Sci. USA 2010, 107, 10926-10931. [CrossRef] [PubMed]

12. Whitelaw, N.C.; Chong, S.; Morgan, D.K.; Nestor, C.; Bruxner, T.J.; Ashe, A.; Lambley, E.; Meehan, R.; Whitelaw, E. Reduced levels of two modifiers of epigenetic gene silencing, Dnmt3a and Trim28, cause increased phenotypic noise. Genome Biol. 2010, 11, R111. [CrossRef] [PubMed]

13. Dalgaard, K.; Landgraf, K.; Heyne, S.; Lempradl, A.; Longinotto, J.; Gossens, K.; Ruf, M.; Orthofer, M.; Strogantsev, R.; Selvaraj, M.; et al. Trim28 Haploinsufficiency Triggers Bi-stable Epigenetic Obesity. Cell 2016, 164, 353-364. [CrossRef] [PubMed]

14. Green, H.; Kehinde, O. An established preadipose cell line and its differentiation in culture. II. Factors affecting the adipose conversion. Cell 1975, 5, 19-27. [CrossRef]

15. Farmer, S.R. Transcriptional control of adipocyte formation. Cell Metab. 2006, 4, 263-273. [CrossRef]

16. Zhang, Q.; Ramlee, M.K.; Brunmeir, R.; Villanueva, C.J.; Halperin, D.; Xu, F. Dynamic and distinct histone modifications modulate the expression of key adipogenesis regulatory genes. Cell Cycle 2012, 11, 4310-4322. [CrossRef]

17. Mikkelsen, T.S.; Xu, Z.; Zhang, X.; Wang, L.; Gimble, J.M.; Lander, E.S.; Rosen, E.D. Comparative epigenomic analysis of murine and human adipogenesis. Cell 2010, 143, 156-169. [CrossRef]

18. Wang, L.; Jin, Q.; Lee, J.E.; Su, I.H.; Ge, K. Histone H3K27 methyltransferase Ezh2 represses Wnt genes to facilitate adipogenesis. Proc. Natl. Acad. Sci. USA 2010, 107, 7317-7322. [CrossRef]

19. Wang, W.; Cai, J.; Wu, Y.; Hu, L.; Chen, Z.; Hu, J.; Chen, Z.; Li, W.; Guo, M.; Huang, Z. Novel activity of KRAB domain that functions to reinforce nuclear localization of KRAB-containing zinc finger proteins by interacting with KAP1. Cell. Mol. Life Sci. CMLS 2013, 70, 3947-3958. [CrossRef]

20. Chen, Y.; Kim, J.; Zhang, R.; Yang, X.; Zhang, Y.; Fang, J.; Chen, Z.; Teng, L.; Chen, X.; Ge, H.; et al. Histone Demethylase LSD1 Promotes Adipocyte Differentiation through Repressing Wnt Signaling. Cell Chem. Biol. 2016, 23, 1228-1240. [CrossRef]

21. Musri, M.M.; Carmona, M.C.; Hanzu, F.A.; Kaliman, P.; Gomis, R.; Parrizas, M. Histone demethylase LSD1 regulates adipogenesis. J. Biol. Chem. 2010, 285, 30034-30041. [CrossRef] [PubMed]

22. Matsumura, Y.; Nakaki, R.; Inagaki, T.; Yoshida, A.; Kano, Y.; Kimura, H.; Tanaka, T.; Tsutsumi, S.; Nakao, M.; Doi, T.; et al. H3K4/H3K9me3 Bivalent Chromatin Domains Targeted by Lineage-Specific DNA Methylation Pauses Adipocyte Differentiation. Mol. Cell 2015, 60, 584-596. [CrossRef] [PubMed]

23. Wakabayashi, K.; Okamura, M.; Tsutsumi, S.; Nishikawa, N.S.; Tanaka, T.; Sakakibara, I.; Kitakami, J.; Ihara, S.; Hashimoto, Y.; Hamakubo, T.; et al. The peroxisome proliferator-activated receptor gamma/retinoid $\mathrm{X}$ receptor alpha heterodimer targets the histone modification enzyme PR-Set7/Setd8 gene and regulates adipogenesis through a positive feedback loop. Mol. Cell. Biol. 2009, 29, 3544-3555. [CrossRef]

24. Chen, Y.S.; Wu, R.; Yang, X.; Kou, S.; MacDougald, O.A.; Yu, L.; Shi, H.; Xue, B. Inhibiting DNA methylation switches adipogenesis to osteoblastogenesis by activating Wnt10a. Sci. Rep. 2016, 6, 25283. [CrossRef]

25. Smas, C.M.; Sul, H.S. Pref-1, a protein containing EGF-like repeats, inhibits adipocyte differentiation. Cell 1993, 73, 725-734. [CrossRef]

26. Smas, C.M.; Sul, H.S. Characterization of Pref- 1 and its inhibitory role in adipocyte differentiation. Int. J. Obes. Relat. Metab. Disord. J. Int. Assoc. Study Obes. 1996, 20 (Suppl. 3), S65-S72.

27. Smas, C.M.; Green, D.; Sul, H.S. Structural characterization and alternate splicing of the gene encoding the preadipocyte EGF-like protein pref-1. Biochemistry 1994, 33, 9257-9265. [CrossRef]

28. Smas, C.M.; Chen, L.; Sul, H.S. Cleavage of membrane-associated pref-1 generates a soluble inhibitor of adipocyte differentiation. Mol. Cell. Biol. 1997, 17, 977-988. [CrossRef]

29. Smas, C.M.; Sul, H.S. Molecular mechanisms of adipocyte differentiation and inhibitory action of pref-1. Crit. Rev. Eukaryot. Gene Expr. 1997, 7, 281-298. [CrossRef]

30. Smas, C.M.; Kachinskas, D.; Liu, C.M.; Xie, X.; Dircks, L.K.; Sul, H.S. Transcriptional control of the pref-1 gene in 3T3-L1 adipocyte differentiation. Sequence requirement for differentiation-dependent suppression. J. Biol. Chem. 1998, 273, 31751-31758. [CrossRef] 
31. Schmidt, J.V.; Matteson, P.G.; Jones, B.K.; Guan, X.J.; Tilghman, S.M. The Dlk1 and Gtl2 genes are linked and reciprocally imprinted. Genes Dev. 2000, 14, 1997-2002. [PubMed]

32. Takada, S.; Tevendale, M.; Baker, J.; Georgiades, P.; Campbell, E.; Freeman, T.; Johnson, M.H.; Paulsen, M.; Ferguson-Smith, A.C. Delta-like and gtl2 are reciprocally expressed, differentially methylated linked imprinted genes on mouse chromosome 12. Curr. Biol. CB 2000, 10, 1135-1138. [CrossRef]

33. Wylie, A.A.; Murphy, S.K.; Orton, T.C.; Jirtle, R.L. Novel imprinted DLK1/GTL2 domain on human chromosome 14 contains motifs that mimic those implicated in IGF2/H19 regulation. Genome Res. 2000, 10, 1711-1718. [CrossRef] [PubMed]

34. Wang, C.; Rauscher, F.J.; Cress, W.D.; Chen, J. Regulation of E2F1 function by the nuclear corepressor KAP1. J. Biol. Chem. 2007, 282, 29902-29909. [CrossRef]

35. Shen, Y.N.; Kim, Y.M.; Yun, C.H.; Moon, Y.S.; Kim, S.H. Transcriptional activation of pref-1 by E2F1 in 3T3 L1 cells. BMB Rep. 2009, 42, 691-696. [CrossRef]

36. Kim, W.J.; Wittner, B.S.; Amzallag, A.; Brannigan, B.W.; Ting, D.T.; Ramaswamy, S.; Maheswaran, S.; Haber, D.A. The WTX Tumor Suppressor Interacts with the Transcriptional Corepressor TRIM28. J. Biol. Chem. 2015, 290, 14381-14390. [CrossRef]

37. Tang, Q.Q.; Otto, T.C.; Lane, M.D. Mitotic clonal expansion: A synchronous process required for adipogenesis. Proc. Natl. Acad. Sci. USA 2003, 100, 44-49. [CrossRef] [PubMed]

38. Nishizuka, M.; Koyanagi, A.; Osada, S.; Imagawa, M. Wnt4 and Wnt5a promote adipocyte differentiation. FEBS Lett. 2008, 582, 3201-3205. [CrossRef] [PubMed]

39. Ross, S.E.; Hemati, N.; Longo, K.A.; Bennett, C.N.; Lucas, P.C.; Erickson, R.L.; MacDougald, O.A. Inhibition of adipogenesis by Wnt signaling. Science 2000, 289, 950-953. [CrossRef]

40. Takada, I.; Kouzmenko, A.P.; Kato, S. Wnt and PPARgamma signaling in osteoblastogenesis and adipogenesis. Nat. Rev. Rheumatol. 2009, 5, 442-447. [CrossRef]

41. Lefterova, M.I.; Lazar, M.A. New developments in adipogenesis. Trends Endocrinol. Metab. 2009, 20, $107-114$. [CrossRef] [PubMed]

42. Mortensen, S.B.; Jensen, C.H.; Schneider, M.; Thomassen, M.; Kruse, T.A.; Laborda, J.; Sheikh, S.P.; Andersen, D.C. Membrane-tethered delta-like 1 homolog (DLK1) restricts adipose tissue size by inhibiting preadipocyte proliferation. Diabetes 2012, 61, 2814-2822. [CrossRef]

43. Wang, Y.; Sul, H.S. Ectodomain shedding of preadipocyte factor 1 (Pref-1) by tumor necrosis factor alpha converting enzyme (TACE) and inhibition of adipocyte differentiation. Mol. Cell. Biol. 2006, 26, 5421-5435. [CrossRef] [PubMed]

44. Baladron, V.; Ruiz-Hidalgo, M.J.; Nueda, M.L.; Diaz-Guerra, M.J.; Garcia-Ramirez, J.J.; Bonvini, E.; Gubina, E.; Laborda, J. Dlk acts as a negative regulator of Notch1 activation through interactions with specific EGF-like repeats. Exp. Cell Res. 2005, 303, 343-359. [CrossRef] [PubMed]

45. Wang, Y.; Zhao, L.; Smas, C.; Sul, H.S. Pref-1 interacts with fibronectin to inhibit adipocyte differentiation. Mol. Cell. Biol. 2010, 30, 3480-3492. [CrossRef]

46. Kim, K.A.; Kim, J.H.; Wang, Y.; Sul, H.S. Pref-1 (preadipocyte factor 1) activates the MEK/extracellular signal-regulated kinase pathway to inhibit adipocyte differentiation. Mol. Cell. Biol. 2007, 27, 2294-2308. [CrossRef]

47. Yevtodiyenko, A.; Carr, M.S.; Patel, N.; Schmidt, J.V. Analysis of candidate imprinted genes linked to Dlk1-Gtl2 using a congenic mouse line. Mamm. Genome Off. J. Int. Mamm. Genome Soc. 2002, 13, 633-638. [CrossRef] [PubMed]

48. Seitz, H.; Royo, H.; Bortolin, M.L.; Lin, S.P.; Ferguson-Smith, A.C.; Cavaille, J. A large imprinted microRNA gene cluster at the mouse Dlk1-Gt12 domain. Genome Res. 2004, 14, 1741-1748. [CrossRef]

49. Hagan, J.P.; O'Neill, B.L.; Stewart, C.L.; Kozlov, S.V.; Croce, C.M. At least ten genes define the imprinted Dlk1-Dio3 cluster on mouse chromosome 12qF1. PLoS ONE 2009, 4, e4352. [CrossRef]

50. Messerschmidt, D.M.; de Vries, W.; Ito, M.; Solter, D.; Ferguson-Smith, A.; Knowles, B.B. Trim28 is required for epigenetic stability during mouse oocyte to embryo transition. Science 2012, 335, 1499-1502. [CrossRef]

51. Tao, Y.; Yen, M.R.; Chitiashvili, T.; Nakano, H.; Kim, R.; Hosohama, L.; Tan, Y.C.; Nakano, A.; Chen, P.Y.; Clark, A.T. TRIM28-Regulated Transposon Repression Is Required for Human Germline Competency and Not Primed or Naive Human Pluripotency. Stem Cell Rep. 2018, 10, 243-256. [CrossRef] [PubMed] 
52. Frost, J.; Monk, D.; Moschidou, D.; Guillot, P.V.; Stanier, P.; Minger, S.L.; Fisk, N.M.; Moore, H.D.; Moore, G.E. The effects of culture on genomic imprinting profiles in human embryonic and fetal mesenchymal stem cells. Epigenetics 2011, 6, 52-62. [CrossRef] [PubMed]

53. Fajas, L.; Landsberg, R.L.; Huss-Garcia, Y.; Sardet, C.; Lees, J.A.; Auwerx, J. E2Fs regulate adipocyte differentiation. Dev. Cell 2002, 3, 39-49. [CrossRef]

54. Dyson, N. The regulation of E2F by pRB-family proteins. Genes Dev. 1998, 12, 2245-2262. [CrossRef] [PubMed]

55. Richon, V.M.; Lyle, R.E.; McGehee, R.E., Jr. Regulation and expression of retinoblastoma proteins p107 and p130 during 3T3-L1 adipocyte differentiation. J. Biol. Chem. 1997, 272, 10117-10124. [CrossRef] [PubMed]

56. Chang, C.W.; Chou, H.Y.; Lin, Y.S.; Huang, K.H.; Chang, C.J.; Hsu, T.C.; Lee, S.C. Phosphorylation at Ser473 regulates heterochromatin protein 1 binding and corepressor function of TIF1beta/KAP1. BMC Mol. Biol. 2008, 9, 61. [CrossRef]

57. Gagne, A.; Hochman, A.; Qureshi, M.; Tong, C.; Arbon, J.; McDaniel, K.; Davis, T.L. Analysis of DNA methylation acquisition at the imprinted Dlk1 locus reveals asymmetry at $\mathrm{CpG}$ dyads. Epigenet. Chromatin 2014, 7, 9. [CrossRef]

58. Takada, S.; Paulsen, M.; Tevendale, M.; Tsai, C.E.; Kelsey, G.; Cattanach, B.M.; Ferguson-Smith, A.C. Epigenetic analysis of the Dlk1-Gtl2 imprinted domain on mouse chromosome 12: Implications for imprinting control from comparison with Igf2-H19. Hum. Mol. Genet. 2002, 11, 77-86. [CrossRef]

59. Langmead, B.; Salzberg, S. Fast gapped-read alignment with Bowtie 2. Nat. Methods 2012, 9, 357-359. [CrossRef]

60. Kim, J.M.; Ogura, A. Changes in allele-specific association of histone modifications at the imprinting control regions during mouse preimplantation development. Genesis 2009, 47, 611-616. [CrossRef]

(C) 2020 by the authors. Licensee MDPI, Basel, Switzerland. This article is an open access article distributed under the terms and conditions of the Creative Commons Attribution (CC BY) license (http://creativecommons.org/licenses/by/4.0/). 